\title{
The Latest Characteristics of Mathematics Education Reform of Compulsory Education Stage in China
}

\author{
Yufeng Guo ${ }^{1}$, Edward A.Silver ${ }^{2}$, Zezhong Yang ${ }^{3, *}$ \\ ${ }^{1}$ School of Mathematical Sciences, Beijing Normal University, Beijing, China \\ ${ }^{2}$ School of Education, University of Michigan, Ann Arbor, United States \\ ${ }^{3}$ School of Mathematics and Statistics, Shandong Normal University, Jinan, China \\ *Corresponding author: zhongzee@163.com
}

Received August 17, 2018; Revised September 20, 2018; Accepted September 28, 2018

\begin{abstract}
The mathematics reform of basic education in China has attracted worldwide attention. Based on the new edition of mathematics curriculum standards of compulsory education stage issued by the Ministry of education in 2011, this paper illustrates the overall framework of China's basic mathematics education reform, analyzes the characteristics of the curriculum objectives, curriculum implementation, and teaching suggestions, especially the part about the mathematics problem-solving. The aim of this study is to promote a comprehensive understanding of mathematics education researchers to the new round of mathematics education reform in China and to enhance the deep communication between Chinese mathematics education and the world mathematics education.
\end{abstract}

Keywords: mathematics, curriculum, standards, reform, problem-solving

Cite This Article: Yufeng Guo, Edward A.Silver, and Zezhong Yang, "The Latest Characteristics of Mathematics Education Reform of Compulsory Education Stage in China." American Journal of Educational Research, vol. 6, no. 9 (2018): 1312-1317. doi: 10.12691/education-6-9-11.

\section{Introduction}

As the foundation of modern science and technology, mathematics has been highly valued by the Chinese government [1]. The Ministry of Education of the People's Republic of China generally makes a relatively large adjustment to basic mathematics education in China every ten years, especially to the mathematics education in compulsory education stage [2].

Consequently, Chinese basic mathematics education has been developing rapidly and achieved remarkable results in recent years [3]. It can be seen from the achievements obtained by Chinese middle school students in the International Mathematics Olympiad and the PISA (Program for International Student Assessment) tests.

Table 1. Document search results

\begin{tabular}{|c|c|c|c|}
\hline Year & 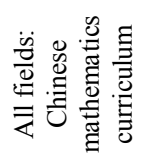 & 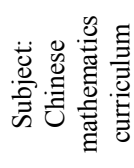 & 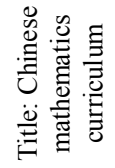 \\
\hline 1960-1969 & 139 & No result & No result \\
\hline $1970-1979$ & 212 & No result & No result \\
\hline 1980-1989 & 391 & No result & No result \\
\hline 1990-1999 & 1308 & 1 & 1 \\
\hline 2000-2009 & 4556 & 3 & 1 \\
\hline 2010- & 5077 & 17 & 3 \\
\hline
\end{tabular}

So the foreign scholars' interest in the research about Chinese basic mathematics education and its reform are increasing yearly $[4,5]$. We ever searched the research works with the library search system of University of Michigan on condition of confining the search conditions for "limit to articles from scholarly journals" "exclude newspaper" "add results beyond this library's holdings" "language: English", the results of every ten years since 1960 are as shown in Table 1.

The Ministry of Education of the People's Republic of China issued the new edition of mathematics curriculum standards of compulsory education stage (MCSCES) in 2011, which marked the beginning of the new round of basic mathematics education reform in China [6,7]. What are the characteristics of this basic mathematics education reform? This is a question that most people concerned and was not answered definitely and clearly yet. For example, although Wang etc. reviewed the recent progress in the reform of mathematics curriculum in China in the early $21^{\text {st }}$ century and introduced the Compulsory Education Mathematics Curriculum (2001 edition, 2011 edition) [8], more in-depth research needs to be done.So this paper will analyze and elaborate on it according to the new edition of MCSCES issued in 2011.

\section{The General Framework of New MCSCES}

The basic mathematics education in China has made great achievements in the past 60 years and accumulated 
valuable experience in mathematics teaching and mathematics teacher training, such as how to help students establish solid mathematical basic knowledge and skills and how to improve mathematics teachers' teaching level by systematic mathematics teacher training etc. Mathematics curriculum in China has also made great progress. However, with the development of the times, there is still something need further improved in many aspects of mathematics curriculum, such as the objectives of the curriculum, the content of the curriculum, the implementation of the curriculum etc.

To reform Chinese traditional mathematics curriculum and contribute to the improvement of the quality of basic mathematics teaching, the new edition of MCSCES gave a fresh framework, which classified its content into five sections, that is Foreword, Course Objectives, Course Content, Course Implementation Suggestions and Appendix. The Foreword section includes the explanations of the nature of the course, the basic idea of the course, and the ideas of the course design. The Course objectives section includes the descriptions of the overall objectives and the objectives of different leaning segments. The Course Content section provides the different learning contents in number and algebra, graphics and geometry, statistics and probability, synthesis and practice for different learning segments. The Course Implementation Suggestions section provides four specific sections including teaching, evaluation, textbooks compile, curriculum resources development and utilization. The Appendix section is the last yet not the least, which includes 82 practical examples to help understanding how to implement the course content [9].

\section{The Characteristics of Course Objectives}

The course objectives undoubtedly are an important section of MCSCES. In the new edition of MCSCES, it included the overall objectives and the objectives of different learning segments and is composed of four areas: knowledge and skills, mathematical thinking, problem-solving, emotion and attitudes. These four areas have their own specific components accordingly, in order to make the course objectives to be clearer and easier to implement.

Taking "knowledge and skills" as an example, MCSCES characterizes it from four different components using process goals and outcome goals. The four components are categorized by course contents, namely numbers and algebra, graphics and geometry, statistics and probability, synthesis and practice. The process goals are expressed in different levels of behavior verbs such as undergo, experience, explore, while the outcome goals are expressed in different levels of behavior verbs such as know, understand, master, apply. These four components of "knowledge and skills" are identified as important targets for development within and across the nine years of compulsory schooling [9]. The details are as shown as Table 2.

In addition, the statement of course objectives have added some new ingredients. The most typical ingredients are "four bases" and "four abilities" in the overall objectives of the course which previously are "double bases" and "two abilities" respectively. "Double bases" refers to basic knowledge and basic skills. "Four bases" refers to basic knowledge, basic skills, basic idea, and basic activity experience. "Two abilities" refers to the ability to analyze and solve problems, while "four abilities" refers to the ability to discover problems, pose problem, analyze problems and solve problems. Those changes tend to find answers to some of the problems that were in former mathematics curriculum. For example, too much emphasis on was put on the knowledge recitation and the acquisition of skills that will neglect the comprehension of mathematics concepts and the accumulation of mathematics experience. Also, too much attention was paid to analyze problems and solve problems while the process to discover problems and pose problems were missed. MCSCES believes that "four bases" and "four abilities" are necessary skills and expertise that students need to adapt to social life and further development [9].

Table 2. The details of "knowledge and skills"

\begin{tabular}{|l|l|}
\hline - Experience the abstraction process of \\
number and algebra, as well as the \\
process of computing and modeling, \\
master the basic knowledge and basic \\
skills of number and algebra. \\
- Experience the process of the abstraction, \\
classification, exploration of nature, \\
transformation, the location determination of \\
the graph, master the basic knowledge and \\
basic skills of graphics and geometry. \\
- Experience the process of collecting and \\
processing the data in real problems, \\
analyzing the problems and getting \\
information by the data, master the basic \\
knowledge and basic skills of statistics and \\
probability. \\
- $\begin{array}{l}\text { Participate in the comprehensive and } \\
\text { practical activities, accumulate the } \\
\text { mathematical activity experience of } \\
\text { comprehensively using mathematical } \\
\text { knowledge, skills and methods to solve } \\
\text { simple problems }\end{array}$ \\
\hline
\end{tabular}

\section{The Characteristics of Course Content}

The course content involved four parts and concerned about 10 keywords. These 10 keywords are number sense, symbolic awareness, space concept, geometry intuitive, data analysis concept, computation ability, reasoning ability, model idea, application awareness, and innovative awareness. Number sense and symbolic awareness mainly correspond to number and algebra contents, space concept and geometry intuitive mainly correspond to graphics and geometry contents, data analysis concept mainly correspond to statistics and probability. Computation ability, reasoning ability, and model idea are mainly cultivated separately in terms of number and algebra, graphics and geometry, statistics and probability content. Application awareness and innovative awareness are involved in the four parts of contents.

Different schooling sections of the course content has clear and specific requirements. Course content focused on basic and logical continuity. Comparing to previous course, a striking change in the contents is the cultivation 
of estimation awareness. For example, "feel the significance of large numbers in the context of life, and can make an estimate", "explore and grasp the rectangular, square area formula, estimate the area of a given simple figure", "estimate the approximate range of an irrational number by rational numbers" etc. [9]. As for the graphics and geometry content, in the preservation of a certain Euclid geometry system, a certain graphics transformation content has been increase. One of the major changes in statistics and probability content is the randomization of data, rather than just emphasizing randomness through probabilistic understanding.

\section{The Characteristics of Course Implementation Suggestions}

The course implementation suggestions put forward some specific requirements on teaching, evaluation, textbooks compile, and curriculum resources. For teaching suggestions, there are seven clear instructions to illustrate that teaching activities are the active participation of teachers and students, exchanges and interaction development process. For evaluation suggestions, there are specific instructions on how to evaluate the basic knowledge and basic skills, mathematical thinking and problem solving, emotion and attitude etc. For textbooks compile, there are specific principles and requirements, for example, mathematics textbooks compile must base on this standard, and different publishing textbooks may form their own orchestration system and reflect their own style and characteristics under certain conditions that teaching material cannot violate the logic of mathematical knowledge etc.

\section{The Characteristics on Mathematics Problem-Solving in MCSCES}

Mathematical problem solving is a topic of great concern. As Chinese students continue to achieve good results in the world mathematics competitions and tests, more and more foreign scholars have paid much attention to the reform and teaching of problem-solving in China. This time the MCSCES did do some particular changing works.

Firstly, MCSCES gave a clear frame structure containing the mathematical problem-solving components and stages of development across grades. Four components of problem solving are identified as important targets for development within and across the nine years of compulsory schooling in China (Stage 1 includes grades 1-3, stage 2 includes grades 4-6, and stage 3 includes grades 7-9): (1) discovering and posing problems, (2) analyzing and solving problems, (3) cooperating and communicating, and (4) evaluating and reflecting [9].

Secondly, MCSCES illustrated the specific implications of developing mathematics problem solving components across grades. MCSCES framework for developing problem solving suggests an expectation of development across the stages of schooling with respect to different aspects of problem solving.
At stage 1, students work with teachers' guidance to pose and attempt to solve problems involving simple mathematical concepts and skills. They try to pose, analyze and solve problems involving methods and ideas they know from everyday experience, and they gradually learn to use additional methods to pose, analyze and solve problems. With guidance from their teachers they gradually realize that different methods can be used to solve problems, they gain experience in cooperating and communicating with classmates in solving problems, and they learn to reflect on the process of solving problems.

At stage 2, students should pose, analyze and solve problems involving more complex mathematical topics, and they should do so in classroom instruction that contains a mixture of teacher-directed and independent student activity. They expand their repertoire of problemsolving methods, and they become more proficient in explaining their own thinking when collaborating or communicating with others.

At stage 3, students pose, analyze and solve problems involving a broad range of mathematical topics, and they do so with considerable autonomy and independence. They should not only explore different ways of analyzing and solving problems but also should come to appreciate the validity and applicability of general methods for solving certain classes of problems involving topics in the basic school curriculum (e.g., fractions, percents, proportions). In addition to improving their proficiency in expressing their own ideas when cooperating and communicating with others, they should be able to analyze and understand the methods and ideas proposed by other students, and they should begin to use mathematical argumentation to evaluate, justify or critique proposed solutions and solution methods.

Thirdly, MCSCES gave concrete example from some aspects of the development stage of mathematical problem solving. The development of problem solving is an important discovery and important theme emphasized in the MCSCES, however, a subject needs further study. MCSCES does not provide all the details that would be required to have a roadmap to guide teachers and students.it does contain a number of ideas that are suggestive and likely to be useful. MCSCES suggests a complex developmental journey that students can follow to become proficient problem solvers. The following is a 'Classifying Buttons' task (see Figure 1) in the MCSCES to help readers know some ideas above [9].

\section{Classifying Buttons}

There are many buttons on the desk. Please classify the buttons into groups according to some characteristic. How many groups are formed? Can you do it using a different characteristic? How many groups for this one? Use words, graphs, tables, or other methods to display your results.

The goal of this task is to make children identify and apply criteria that can be used to classify the buttons in the collection. In this case, color, shape, and number (of holes) could each be used to partition the collection of buttons. There are a number of observations that children would typically be expected to make about this basic classification activity, such as noticing that the resulting groups will be the same for a given criterion regardless of the order in which the buttons in the collection are sorted. 
That is, regardless of how we classify the buttons shown in Figure 1 according to shape, the result will always be the same: one group containing 10 circular buttons and another containing 14 square buttons. Another important observation is that when we classify the buttons using different characteristics we get different groupings. That is, the result when we classify the buttons according to color is two groups ( 13 yellow and 11 blue), which is different from the final result when we classify according to shape (10 circular and 14 square).

MCSCES makes the following point: "This is an activity which fits for every grade at stage 1 while there are differentiated requirements for each grade within stage 1" [9]. Stage 1 in China corresponds to grades 1-3, and so this statement suggests a developmental notion regarding problem solving as growing across grades. In particular, MCSCES offers the following suggestions regarding this task: "Teachers should first help students select one criterion, such as color. Later, teachers should assist students to classify on the basis of two criteria simultaneously, such as color and shape. Finally, teachers should assist students to classify successively using all three criteria: color, shape, and number of buttonholes" [9].
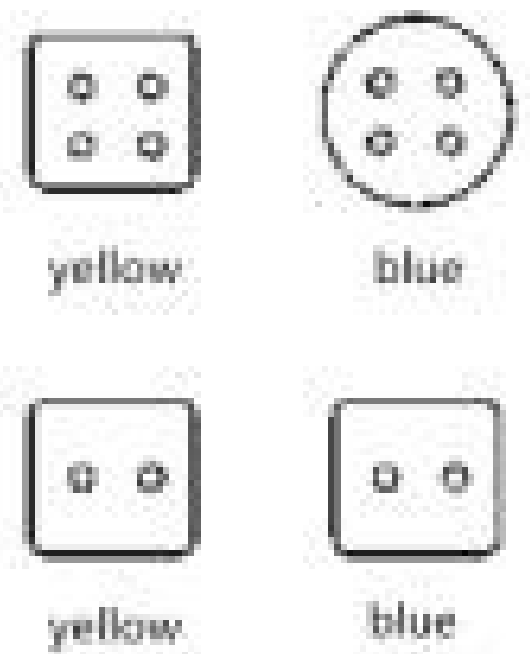

\section{blut}
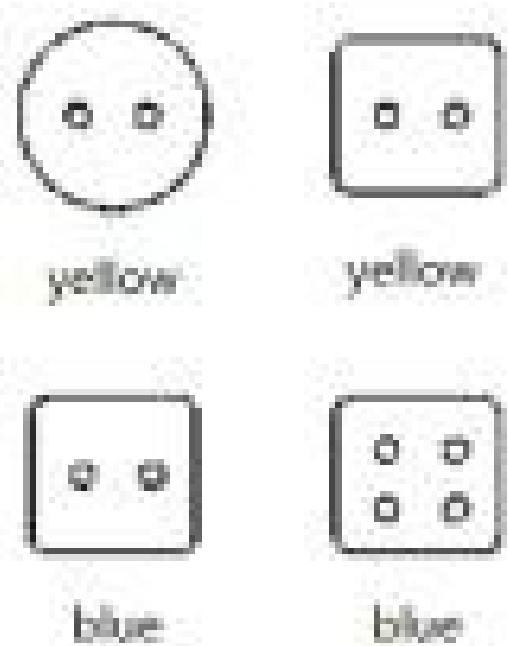
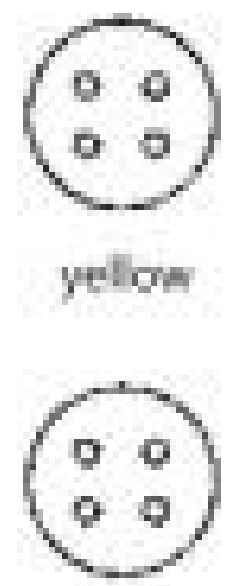

blue
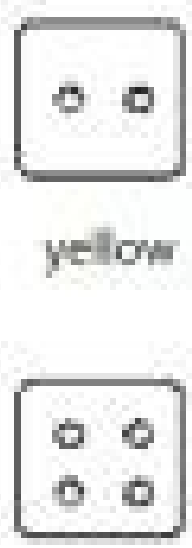

blue
Corresponding to the increasing complexity of the classification activity, teachers are encouraged to ask questions that draw students' attention to important facets of the task:

1) If we use only one criterion to classify the buttons, what will be the result? Is it always the same? [What are the different ways we might interpret "the same"? How about same result regardless of which buttons we begin with? How about same result regardless of which criterion we use?]

2) If we classify the buttons using two criteria in succession, what will be the result? Is it always the same? [For example, if classify first by color and then by the number of buttonholes, do we get the same result as classifying first by shape and then by color?] When do we get the same result? When do we get different results?

3) If we classify the buttons using three criteria (color, number and shape) in succession, what will be the result? Is it always the same? The Figure 2 shows the result of classifying the buttons first by color, then by number of buttonholes, and finally by shape. Suppose you classify using a different order, will the final result be different or the same? Why?
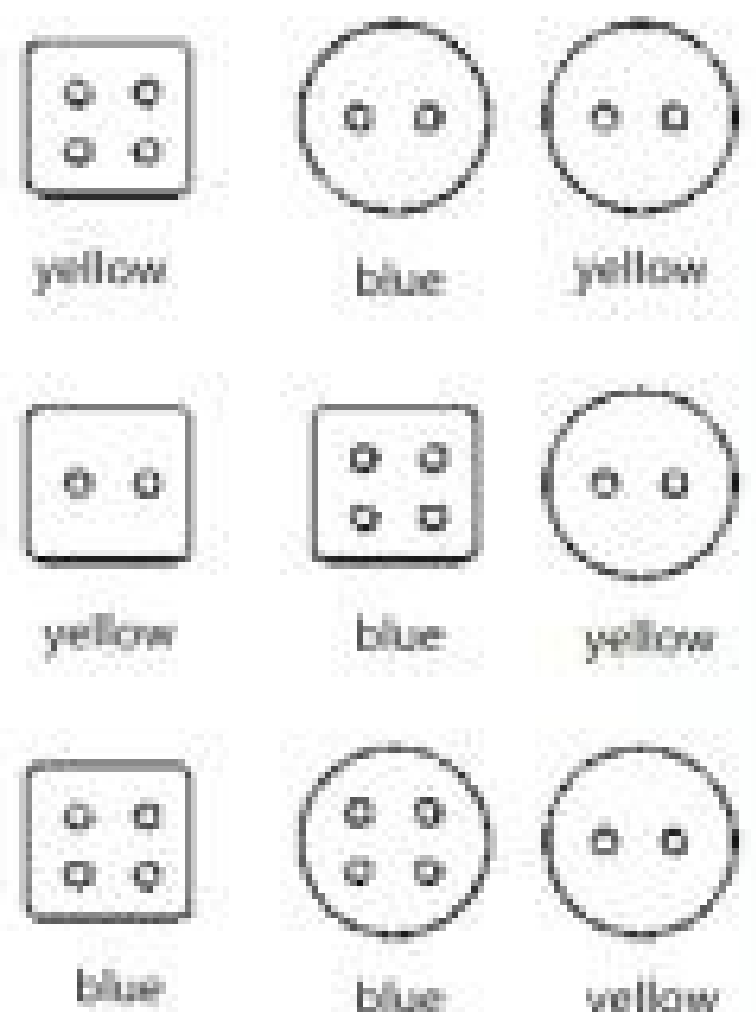

blue
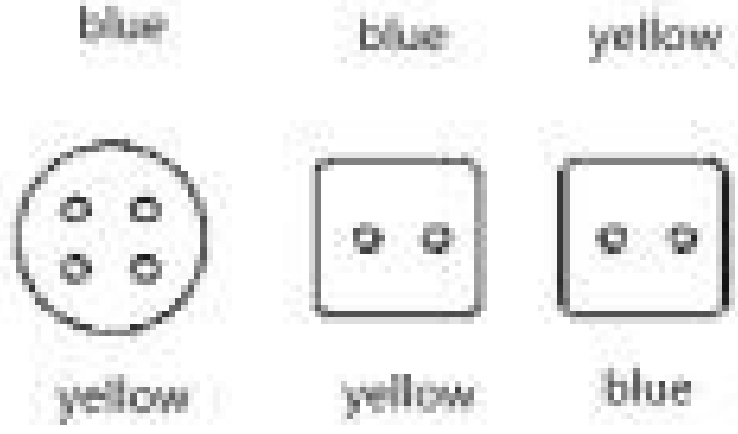

yellow

Figure 1. Classifying Buttons Task 


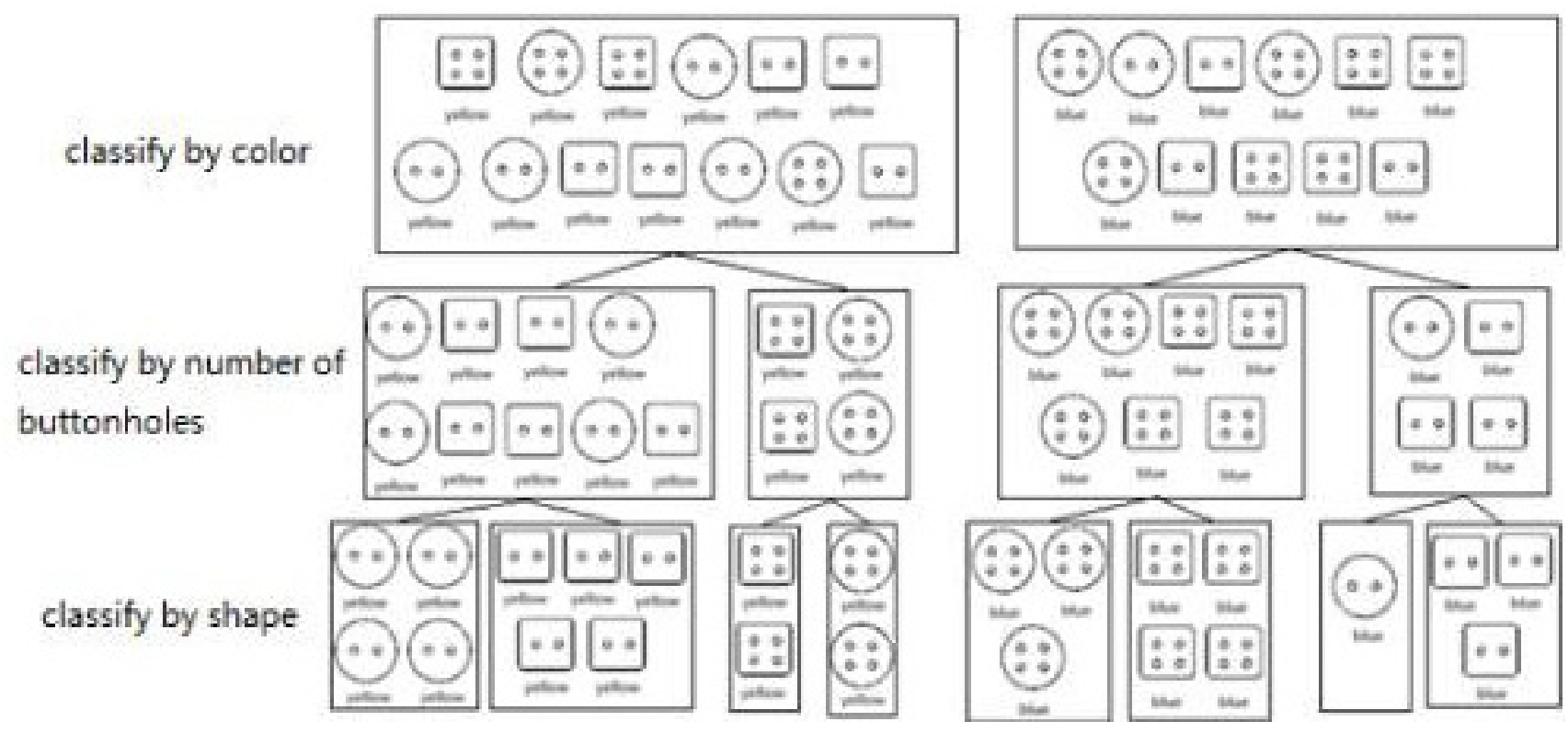

Figure 2. Outcome of classifying successively by color, then number, then shape

\section{Discussion and Conclusion}

It could be seen from the analysis above that the new edition of MCSCES changed a lot and put forward many new ideas. These new changes undoubtedly will advance the development of Chinese basic mathematics education. However, it should be careful that this is not a recipe or roadmap for mathematics teachers.

First, the orientation for the compulsory education in China is basic, universal and developmental, that is, what the MCSCES really concerned is the basic and development. which expects students to observe the world around in mathematics view, think mathematically by means of mathematical thinking, and express the real world in mathematical language, that is, students will obtain and develop their mathematics key competencies that benefit themselves for their lifelong. Although Chinese students have achieved excellent results in PISA test of math and science literacy, some researchers believe there is still room for Chinese students to improve their mathematical competencies in comparison to solid math basic knowledge and skills. Therefore, in the reform of the content of the curriculum, MCSCES pays more attention to the core knowledge of mathematics and the setting of the mainstream knowledge, focusing on the mathematical generalization. For the implementation of the curriculum, MCSCES emphasizes that students should experience the occurrence and development process of knowledge, understand the essence of knowledge and integration between mathematical knowledge, pay attention to the unity of process teaching and result teaching instead of paying too much attention to result teaching.

Second, MCSCES put forward a very important and meaningful idea about the development stage of the target set for mathematics problem-solving. However, at some point, these are just pieces of documentation. The description of its stages of development is still a new topic and deserves our further discussion and research.

1. With respect to discovering and posing problems, MCSCES suggests that students should progress from highly guided activities in the primary grades involving problems based on familiar everyday life settings and involving simple mathematical ideas to largely independent activities in the upper basic and middle grades involving more abstract problem settings and more complex mathematical ideas. Then, what is the difference between the teachers' guidance at different stages? Is there any detail explanations to state what highly guided activities are and what is independent activities?

2. With regard to analyzing and solving problems, MCSCES suggests that students should develop from simply finding solutions to problems under the guidance of their teachers to becoming autonomous problem solvers who can determine the mathematical appropriateness of problem solutions and solution methods they produce. So, how can we help students to become autonomous problem solvers? What should we do at different stages?

3. With respect to cooperation and communication, MCSCES suggests that students progress from simply experiencing the processes of cooperating and communicating to becoming proficient in expressing their own ideas and in learning to understand those expressed by others. Then, how should teachers guide students to express mathematically at different stages? What are the major differences between the lower grade students and senior high school students in mathematics cooperation?

4. Regarding reflection on problem solving, MCSCES suggests that students progress from simply judging the reasonableness of their own results to reflecting on and evaluating the mathematical validity of solutions, methods, and arguments proposed by others. So, how could students gradually develop the habit of retrospection?

Interest has grown in recent years among teachers and curriculum developers in identifying learning trajectories or learning progressions for a host of mathematical topics in the curriculum, however, too little attention has been given to the important matter of problem-solving 
development across grades. It has become increasingly apparent that we lack clarity about what such a developmental trajectory might be for the all-important topic of mathematical problem solving.

\section{Support}

Support by China Scholarship Council (Grant No.201706045021).

\section{References}

[1] State Council of the PRC., Outline of National Medium and Long Term Educational Reform and Development Plan (2010-2020). Retrieved July, 12, 2018, from

http://www.moe.gov.cn/srcsite/A01/s7048/201007/t20100729 171 904.html.

[2] Lv, S., History of Chinese Middle School Mathematics Curriculum. Beijing: People Education Press.2013.

[3] Li, W., History and Future: Some Thoughts on the Mathematics Curriculum Reform in Basic Education. Mathematics teaching, 2013, (11): 2.
[4] McGatha, M. B. \& SheffieldL, L. J., Mighty Mathematicians: Using Problem Posing and Problem Solving to Develop Mathematical Power. Teaching Children Mathematics, 2006, 13(2): 79-85.

[5] Mary K. S., Smith, M. S., Henningsen, M. \& Silver, E. A., Implementing Standards-based Mathematics Instruction: A Casebook for Professional Development (Second Edition). New York: Teachers College Press and National Council of Teachers of Mathematics.2009.

[6] Zhu, L. Sh., Shen, N. H. \& Song, N. Q., Educational Thinking on the Connotation Extension of the "Double Base" of Mathematics Curriculum Standards. Curriculum, Teaching Material and Method, 2012, 32 (05): 41-45.

[7] Shi, N. Zh., Ma, Y. P., Liu, X. M., Compulsory Education Mathematics Curriculum Standard Revision Process and Main Content. Curriculum, Teaching Material and Method, 2012, 32 (03): $50-56$

[8] Wang, L., Liu, Q., Du, X.,\& Liu,J., Chinese Mathematics Curriculum Reform in the 21st Century: A review. EURASIA Journal of Mathematics Science and Technology Education, 2017, 13 (8): 5311-5326.

[9] Ministry of Education of the People's Republic of China. Compulsory Education Mathematics Curriculum Standards (2011 version). Beijing: Beijing Normal University Publishing Group, 2011. 